\title{
Prospective comparison of the impact of robotic-assisted laparoscopic radical prostatectomy versus open radical prostatectomy on health- related quality of life and decision regret
}

\author{
B. Joyce Davison, RN, PhD; $;^{*}$ Andrew Matthew, PhD, CPsych; ${ }^{\dagger}$ Abbie M. Gardner MSc and Applied Statistics ${ }^{\dagger s}$
}

*College of Nursing, University of Saskatchewan, Saskatoon, SK; 'Department of Surgery, University of Toronto, Toronto, ON; §Department of Psychiatry, University of Toronto, Toronto, ON

Cite as: Can Urol Assoc J 2014;8(1-2):e68-72. http://dx.doi.org/10.5489/cuaj.480

Published online January 14, 2014.

\section{Abstract}

Introduction: There is no conclusive evidence that the roboticassisted laparoscopic radical prostatectomy (RARP) is superior to conventional open radical prostatectomy (ORP) when it comes to recovery of urinary and sexual function, and that the former surgical option results in less decision regret.

Methods: Patients scheduled for both surgical procedures were surveyed prior to surgery, and then again at 6 and 12 months following treatment using the sexual and urinary modules of the Expanded Prostate Cancer Index Composite (EPIC) measure. Decision regret was measured at 12 months. Propensity score regression adjustment was used to account for differences between treatment groups by summarizing all covariate information into a single probability and to simulate randomization.

Results: At 12 months, urinary summary scores approached baseline levels, while urinary bother scores had returned to baseline. Sexual summary and bother mean scores decreased by about half of what they were at baseline for both treatment groups at 6 and 12 months. No significant differences in the groups' sexual summary and bother domains were identified at either 6 or 12 months. Both groups' scores for decision regret were low. Moderate correlations $\left(r^{2}\right.$ range -0.333 to -0.368 ) were between current levels of urinary and sexual function and decision regret at 12 months.

Conclusion: The results of our study found no significant difference in health-related quality of life outcomes based on surgical procedure at 12 months. Moreover, patients in both groups reported low levels of decision regret at 12 months. Further multi-site prospective studies are required to address this study's limitations.

\section{Introduction}

The robotic-assisted laparoscopic radical prostatectomy (RALRP) is an increasingly emergent surgical approach to treating localized prostate cancer. Since its introduction, RALRP has received widespread acceptance by patients and physicians. Given the minimally invasive nature of robotic surgery performed with the da Vinci system, research to date has mainly reported on the beneficial impact to perioperative morbidity of RALRP compared to open radical prostatectomy (ORP). Recent findings support that RALRP does result in a shorter hospital stay, but there is no conclusive evidence that this procedure results in earlier return to physical activity or improved disease outcomes. ${ }^{1}$ Perioperative outcomes appear to favour a less invasive approach, but further comparative assessment of long-term functional and oncological efficacy is required. ${ }^{2}$

The indolent nature of prostate cancer makes healthrelated quality of life (HRQoL) an important component for evaluating treatments currently offered to patients with localized prostate cancer. QoL studies that use validated questionnaires help to define the course of patient recovery. ${ }^{3}$ Urinary and sexual function are the 2 most common patient concerns after radical prostatectomy regardless of the surgical procedure, ${ }^{4}$ with better baseline scores associated with better postoperative function. ${ }^{5}$ Although most patients with localized prostate cancer do not regret their treatment decision, ${ }^{6-8}$ urinary and sexual function have been found to independently predict decision regret following primary treatment. ${ }^{7,9}$

An emerging body of literature is becoming available to guide patient- and physician-treatment decision-making based on patient reported HRQoL. This data are especially important when new treatments, such as RARP, are introduced. We measure and compare the impact of the RARP and ORP surgical procedures on patient sexual and urinary function, and determine the impact of these outcomes on decision regret. 


\section{Methods}

A consecutive sample of outpatients scheduled to undergo an ORP or RALRP at the Vancouver Prostate Centre between November 2007 and June 2009 were approached to participate in a prospective assessment of urinary and sexual function prior to and after surgery. Two urologists performed the RARP procedure using the da Vinci Robot (Intuitive Surgical Inc., Sunnyvale, CA), and 2 urologists performed the ORP procedure in this clinical setting. All urologists had more than 15 years of experience. About 250 radical prostatectomies are performed annually at this centre. Inclusion criteria were clinically localized prostate cancer disease (TMN stages T1 or T2). Exclusion criteria were no previous treatment for prostate cancer, and no history of neoadjuvant or adjuvant hormonal treatment.

This study received ethical approval by the local ethics committees, and informed consent was obtained at least 1 month prior to surgery. All patients received standard preoperative discussion with their urologist, and were informed that the procedure was new at the centre. Patients answered the sexual and urinary modules of the Expanded Prostate Cancer Index Composite (EPIC) before surgery, and then again at 6 and 12 months following surgery. Data from the EPIC questions pertaining to patient use of sexual aids were also collected at each time point. There were no structured programs to address sexual function and urinary incontinence during the course of the study. The Decision Regret Scale was used to measure distress or remorse after the decision to have surgery at 1 year after treatment. This scale uses a 5 -item self-reported Likert scale ( $1=$ strongly agree to $5=$ strongly disagree). A Cronbach's Alpha coefficient greater than 0.91 has previously been reported with this patient population. ${ }^{10,11}$ Questionnaires were mailed to patients in postage-paid envelops at the appropriate time points. Patients received up to 2 reminder telephone calls from the research assistant.

\section{Statistical analyses}

Both the EPIC and Decision Regret questionnaires were scored according to authors' instructions. Separate models were estimated for sexual and urinary HRQoL domains. Since the study design precluded random assignment to surgical procedure, propensity score regression adjustments were used to balance treatment groups and simulate randomization. ${ }^{12,13}$ Propensity analysis was used to account for differences between treatment groups by summarizing all covariate information into a single probability. Preoperative HRQoL measures, age, Gleason score, and prostate-specific antigen (PSA) levels were used to calculate the propensity score. Repeated measures analysis of variance (ANOVA) adjusting for propensity score were used to assess surgical treatment differences in HRQoL. Nerve-sparing status and use of phospodiesterase-5 (PDE5) inhibitors were used as additional covariates for the sexual domain models. The Student t-test and chi-square were used to assess demographic and background characteristics of the 2 surgical groups. Statistical significance was determined using at 2 -tailed test at the significance level of $p<0.05$. Pearson's correlation coefficient tests were used to test for relationships among unadjusted urinary and sexual scores and total decision regret scores at 1 year.

\section{Results}

During the study period, 142 (42\%) out of 335 patients underwent RARP and 192 (57\%) underwent ORP. Of these patients, 78/142 (55\%) robotic and 73/192 (38\%) conventional prostatectomy patients consented and participated in this study by returning the questionnaires at all 3 measurement points; we had a total response rate of $58 \%$. Twentynine patients were recruited during the first 6 months of implementing the RARP procedure at this setting.

In total, we had 151 respondents (Table 1 ). The mean age was 62.8 (standard deviation [SD] 6.9) years for patients in the ORP group and 61.3 (SD 6.4) years in the RARP group. A significantly higher proportion of patients in the RALRP group had 1 or both nerves spared $(p<0.001)$, lower Gleason scores $(p<0.001)$ and lower PSA levels $(p<0.04)$ compared to patients in the ORP group.

\section{Urinary summary and urinary bother}

The urinary domain scores did not significantly differ between the 2 surgical procedures at baseline, 6 or 12 months post-treatment when adjusting for propensity score. Repeated measures ANOVA showed a within-subject difference for urinary summary and bother. Mean scores at 6 and 12 months demonstrated that the urinary summary in both treatment modality groups approached baseline levels, while mean urinary bother scores for both surgical treatment groups returned to baseline at 12 months post-surgery (Table 2).

\section{Sexual summary and sexual bother}

Repeated measures ANOVA adjusting for nerve-sparing status and use of PDE5 inhibitors demonstrated significant within-subject difference in mean HRQoL across time for both the sexual summary and sexual bother domains $(p<0.001)$. The mean scores decreased by about half of what they were at baseline for both treatment modalities at 6 and 12 months (Table 2). The sexual summary and sexual bother domains were not significantly different for patients in the RALRP group compared to the ORP group at either 6 or 12 months. 


\begin{tabular}{|c|c|c|c|c|c|}
\hline \multirow[t]{2}{*}{ Variable } & \multicolumn{2}{|c|}{$\begin{array}{c}\text { ORP (Open) } \\
n=73\end{array}$} & \multicolumn{2}{|c|}{$\begin{array}{c}\text { RALRP (Robotic) } \\
n=78\end{array}$} & \multirow[t]{2}{*}{$\begin{array}{c}p \\
\text { value }\end{array}$} \\
\hline & $\mathbf{n}$ & (\%) & $\mathbf{n}$ & (\%) & \\
\hline Age (mean/SD) & 62.8 & (6.9) & 61.3 & (6.4) & 0.17 \\
\hline Educational Attainment & & & & & 0.57 \\
\hline Less than high school & 12 & $(17)$ & 9 & $(12)$ & \\
\hline High school/trade school & 16 & $(22)$ & 24 & (31) & \\
\hline Community college & 17 & (24) & 15 & (19) & \\
\hline Undergraduate & 8 & (11) & 12 & (16) & \\
\hline $\begin{array}{l}\text { Graduate/professional } \\
\text { degree }\end{array}$ & 19 & $(26)$ & 17 & $(22)$ & \\
\hline Marital Status & & & & & 0.05 \\
\hline Married/cohabitating & 60 & (82) & 65 & (83) & \\
\hline Significant relationship & 2 & (3) & 8 & $(10)$ & \\
\hline No current relationship & 11 & (15) & 5 & (6) & \\
\hline Employment & & & & & 0.06 \\
\hline Full-time & 23 & (32) & 40 & (51) & \\
\hline Part-time & 8 & $(11)$ & 10 & $(13)$ & \\
\hline Retired & 39 & (53) & 26 & (33) & \\
\hline Unemployed/looking & 3 & (4) & 2 & (3) & \\
\hline Ethnicity & & & & & 0.52 \\
\hline Caucasian & 64 & (88) & 68 & (87) & \\
\hline Asian & 5 & (7) & 8 & $(10)$ & \\
\hline Other & 4 & (5) & 2 & (3) & \\
\hline Clinical Stage & & & & & 0.64 \\
\hline T1 & 30 & (41) & 36 & (46) & \\
\hline $\mathrm{T} 2$ & 38 & $(52)$ & 39 & $(50)$ & \\
\hline T3 & 5 & (7) & 3 & (4) & \\
\hline PSA (mean/SD) & 7.8 & $(5.8)$ & 6.2 & $(2.8)$ & 0.04 \\
\hline Gleason score (mean/SD) & 7.0 & $(1.0)$ & 6.6 & $(0.6)$ & 0.001 \\
\hline Nerves Spared & & & & & 0.001 \\
\hline Unilateral & 13 & (18) & 16 & (21) & \\
\hline Bilateral & 30 & $(41)$ & 54 & (69) & \\
\hline None & 27 & (37) & 8 & $(10)$ & \\
\hline Unknown & 3 & (4) & 0 & $(0.0)$ & \\
\hline
\end{tabular}

SD: standard deviation; PSA: prostate-specific antigen; ORP: open radical prostatectomy; RALRP: robotic-assisted laproscopic radical prostatectomy.

Patients who had either 1 or 2 nerves spared reported an overall higher mean sexual quality of life score $(\bar{x}=39.4$, $\mathrm{SD}=26.6)$ compared to patients with no/unknown nerves spared $(\bar{x}=27.6, \mathrm{SD}=23.6)$. The same trend occurred for patients using a PDE5 inhibitor $(\bar{x}=40.5$, SD 25.4) com- pared to patients with no use of PDE5 inhibitors $(\bar{x}=30.7$, SD 26.7).

\section{Decision regret}

The mean total decision regret score of patients in the RARP was 19.34 ( $\mathrm{SD}=20$ ) and the ORP group $21.32(\mathrm{SD}=24.6)$. The groups' total decision regret scores were low and did not differ significantly $(p=0.59)$ at 1 year (Table 3$)$. The decision regret scores were moderately $(0.30 \leq r<0.50)^{14}$ correlated with overall urinary, urinary bother, overall sexual, and sexual bother for patients in the ORP group at 1 year, with Pearson's $r$ range -0.333 to -0.368 (Table 4). The negative coefficient indicates that the higher the HRQoL at 1 year, the lower the decision regret score or the lower the level of regret. In the RARP group, the decision regret scores were weakly correlated with overall urinary, overall sexual, and sexual bother at 1 year with $r$ range -0.239 to -0.274 . There was no significant correlation between the total decision regret score and urinary bother at 1 year for patients in the RARP group.

\section{Discussion}

The purpose of this study was to explore whether patients who decide to undergo radical prostatectomy with either the robotic technique or traditional open approach differ with regard to HRQoL and decision regret. We found that urinary and sexual domain scores did not differ significantly between groups at 6 or 12 months when adjusting for propensity score; the low decision regret scores at 1 year also did not differ between groups.

Comparing ORP, RARP and laparoscopic prostatectomy (LRP), Finkelstein and colleagues ${ }^{15}$ concluded that the most significant outcomes of cure, continence, and potency are no better with LRP or RARP than with conventional ORP, and in experienced hands the ORP remains the gold standard. One year after prostatectomy, the urinary summary score of patients in our study did not return to baseline. However, the mean urinary bother scores had returned to baseline function at 1 year. Other investigators also have reported a similar pattern of urinary recovery in long-term studies. ${ }^{16,17}$ Recently, Tseng and colleagues, ${ }^{18}$ in a study of robotic prostatectomy outcomes using the EPIC, also report-

Table 2. Adjusted health-related quality of life scores at baseline, 6 months and 12 months following radical prostatectomy

\begin{tabular}{|c|c|c|c|c|c|c|}
\hline \multirow[b]{2}{*}{ HROOL domain } & \multicolumn{2}{|c|}{ Baseline (Mean/SD) } & \multicolumn{2}{|c|}{6 Months (Mean/SD) } & \multicolumn{2}{|c|}{12 Months (Mean/SD) } \\
\hline & $\begin{array}{c}\begin{array}{c}\text { ORP (Open) } \\
n=73\end{array} \\
\text { (n) }\end{array}$ & $\begin{array}{c}\begin{array}{c}\text { RALRP (Robotic) } \\
n=78\end{array}\end{array}$ & $\begin{array}{c}\text { ORP (Open) } \\
n=73\end{array}$ & $\begin{array}{c}\begin{array}{c}\text { RALRP (Robotic) } \\
\text { n=78 }\end{array} \\
\text { (n) }\end{array}$ & $\begin{array}{c}\text { ORP (Open) } \\
n=73\end{array}$ & 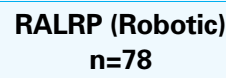 \\
\hline Urinary summary & $88.9(11.6)$ & $87.6(12.0)$ & $78.8(17.7)$ & $77.4(18.2)$ & $83.6(17.1)$ & $81.3(14.4)$ \\
\hline Urinary bother & $84.2(16.0)$ & $83.8(15.1)$ & $78.8(18.5)$ & $77.9(19.2)$ & $83.1(18.0)$ & 82.7 (13.9) \\
\hline Sexual summary & $54.6(30.1)$ & $57.1(25.4)$ & $20.7(17.3)$ & $27.2(17.2)$ & $25.4(19.9)$ & $32.6(20.8)$ \\
\hline Sexual bother & $64.5(36.4)$ & $66.2(31.4)$ & $28.5(24.5)$ & $35.0(23.6)$ & $34.6(28.7)$ & $42.8(28.3)$ \\
\hline
\end{tabular}




\begin{tabular}{|c|c|c|c|c|}
\hline \multirow[b]{2}{*}{ Items } & \multicolumn{4}{|c|}{ n (\%) } \\
\hline & & $\begin{array}{l}\text { Agree or } \\
\text { strongly } \\
\text { agree }\end{array}$ & Neither & $\begin{array}{l}\text { Disagree } \\
\text { or } \\
\text { strongly } \\
\text { disagree }\end{array}$ \\
\hline \multirow{2}{*}{$\begin{array}{l}\text { 1. It was the right } \\
\text { decision. }\end{array}$} & ORP & $59(81)$ & $10(14)$ & $4(5)$ \\
\hline & RALRPa & $72(94)$ & $3(4)$ & $2(3)$ \\
\hline \multirow{2}{*}{$\begin{array}{l}\text { 2. I regret the decision } \\
\text { that was made. }\end{array}$} & ORP & $10(14)$ & $11(15)$ & $52(71)$ \\
\hline & $\mathrm{RALRP}$ & $8(10)$ & $5(7)$ & $63(83)$ \\
\hline \multirow{2}{*}{$\begin{array}{l}\text { 3. I would make the } \\
\text { same decision if I } \\
\text { had to do it again. }\end{array}$} & ORP & $56(77)$ & $11(15)$ & $6(8)$ \\
\hline & RALRPb & $63(83)$ & $9(12)$ & $4(5)$ \\
\hline \multirow{2}{*}{$\begin{array}{l}\text { 4. The decision did me } \\
\text { a lot of harm. }\end{array}$} & ORPa & $8(11)$ & $19(26)$ & $45(63)$ \\
\hline & RALRP & $11(14)$ & $9(12)$ & $56(74)$ \\
\hline \multirow{2}{*}{$\begin{array}{l}\text { 5. The decision was a } \\
\text { wise one. }\end{array}$} & ORPa & $55(76)$ & 12 (17) & $5(7)$ \\
\hline & & 67 ( 88) & 7 (9) & $2(3)$ \\
\hline
\end{tabular}

ed that although baseline urinary function declined at 12 months, urinary bother scores approached baseline levels.

Overall sexual domain scores were not significantly different between surgical groups at either the 6- or 12-month measurement time points. However, our results showed that at 6 months, the mean quality of life for those patients using an erectile aid in the sexual summary domain was higher for patients in the ORP group. Since the sample size for erectile aid users in the ORP group was half of what it was for the RARP group, it is difficult to determine if there really was a difference. Having one or both nerves preserved and using a PDE5 inhibitor were found to have a positive impact on the groups' sexual summary domain scores.

The results of this study did not demonstrate a significant difference between the groups' overall mean decision regret score at 1 year. In our study, 14\% of patients in the ORP group and $10 \%$ of patients in the RARP group regretted their treatment choice. Similarly, Schroeck and colleagues ${ }^{8}$ found that $15 \%$ of patients who underwent ORP regretted their treatment decision compared to $24 \%$ of patients who had undergone RARP. One explanation for the higher number of men experiencing regret in Schroeck's study may be related to the differences between the surgical groups' length of time since treatment, age, Gleason score, and number of patients on hormone therapy. Furthermore, these authors ${ }^{8}$ used 1 item to measure decision regret, whereas we used a 5 -item validated measure in this study. Further assessments of decision regret have to ensure that only validated measures are used so that results can be compared.

Our study had several limitations. Similar to most studies comparing these 2 surgical treatment modalities, this was not a randomized study. It was therefore necessary to use propensity score regression adjustment to balance treat-

\begin{tabular}{|c|c|c|c|c|c|}
\hline Group & & $\begin{array}{l}\text { Overall } \\
\text { urinary }\end{array}$ & $\begin{array}{l}\text { Urinary } \\
\text { bother }\end{array}$ & $\begin{array}{l}\text { Overall } \\
\text { sexual }\end{array}$ & $\begin{array}{l}\text { Sexual } \\
\text { bother }\end{array}$ \\
\hline \multirow[t]{2}{*}{ RALRP $(n=78)$} & $r$ & -0.239 & -0.152 & -0.263 & -0.274 \\
\hline & $p$ value & 0.037 & 0.190 & 0.023 & 0.019 \\
\hline \multirow[t]{2}{*}{ ORP $(n=73)$} & $r$ & -0.333 & -0.368 & -0.364 & -0.357 \\
\hline & $p$ value & 0.005 & 0.002 & 0.002 & 0.002 \\
\hline
\end{tabular}

ment groups and simulate randomization. To address this issue, we would suggest using matched patients according to disease characteristics and procedure in future studies. Significant correlations also were identified between total decision regret scores at 1 year and several of the urinary and sexual domains. However, these correlations were moderate to weak; therefore, one must view these results with caution as to their clinical relevance. In addition, since urologists conducted all preoperative treatment discussions with their patients, a bias might have occurred which could have affected decision regret scores. Future studies should also include complications related to surgical procedure and pathological stage which could have had an influence on decision regret scores. Lastly, the low response rate was unexpected. Future studies may explore the use of using both paper and online versions as a method of getting a better response.

\section{Conclusion}

Most evidence comparing RARP with ORP procedures shows that patients will have a better HRQoL if they chose the robotic procedure, but our results suggest that this may not be the case. We also found that both groups reported low levels of decision regret. We suggest that institutional specific data on HRQoL outcomes are essential to share with patients considering either of these surgical treatments for localized prostate cancer. Furthermore, we need to assess if more time after surgery (increases in the time to recovery of urinary and sexual function) affects decision regret. Prospective multicentre studies are warranted to address these limitations.

Acknowledgements: Dr. M. Gleave, Dr. Peter Black and Dr. Alan So for patient access to conduct this study.

Competing interests: Dr. Davison, Dr. Matthew and Dr. Gardner all declare no competing financial or personal interests.

This paper has been peer-reviewed. 
Davison et al.

\section{References}

1. Schroeck FR, Krupski TL, Stewart SB, et al. Pretreatment expectations of patients undergoing robotic assisted laparoscopic or open retropubic radical prostatectomy. J Urol 2012;187:894-8. http://dx.doi. org/10.1016/i.juro.2011.10.135

2. Cathcart $P$, Murphy DG, Moon D, et al. Perioperative, functional and oncological outcomes after open and minimally invasive prostate cancer surgery: Experience from Australasia. BJU Int 2011;107:11-9. http://dx.doi.org/10.1111/j.1464-410X.2011.10053.x

3. Boorijan SA, Gettman MT. Advances in robotic prostatectomy. Curr Urol Rep 2008;9:250-6. http:// dx.doi.org/10.1007/s11934-008-0043-y

4. Sanda MG, Dunn RL, Michalski J, et al. Quality of life and satisfaction with outcome among prostatecancer survivors. N Engl J Med 2008;358:1250-61. http://dx.doi.org/10.1056/NEJMoo074311

5. Shikanov SA, Eng MK, Bernstein AJ, et al. Urinary and sexual quality of life 1 year following robotic assisted laparoscopic radical prostatectomy. J Urol 2008;180:663-7. http://dx.doi.org/10.1016/i. juro.2008.04.013

6. Clark JA, Inui TS, Silliman RA, et al. Patients' perceptions of quality of life after treatment for early prostate cancer. J Clin Oncol 2003;21:3777-84. http://dx.doi.org/10.1200/JC0.2003.02.115

7. Hu JC, Kwan L, Saigal CS, et al. Regret in men treated for localized prostate cancer. J Urol 2003;169:227983. http://dx.doi.org/10.1097/01.ju.0000065662.52170.6f

8. Schroeck FR, Krupski TL, Sun L, et al. Satisfaction and regret after open retropubic or robot-assisted laparoscopic radical prostatectomy. Eur Urol 2008;54:785-93. http://dx.doi.org/10.1016/j.eururo.2008.06.063

9. Diefenbach MA, Mohamed NE. Regret of treatment decision and its association with disease-specific quality of life following prostate cancer treatment. Cancer Invest 2007;25:449-57. http://dx.doi. org/10.1080/07357900701359460
10. Brehaut JC, $O^{\prime}$ Connor AM, Wood TJ, et al. Validation of a decision regret scale. Med Decis Making 2003;23:281-92. http://dx.doi.org/10.1177/0272989X03256005

11. Davison BJ, So Al, Goldenberg SL. Quality of life, sexual function and decision regret one year following surgical treatment of localized prostate cancer. BJU Int 2007;100:780-5. http://dx.doi.org/10.1111/ j.1464-410X.2007.07043.x

12. Rosenbaum PR, Rubin DB. The central role of the propensity score in observational studies for causal effects. Biometrika 1983;70:41-55. http://dx.doi.org/10.1093/biomet/70.1.41

13. Leslie S, Thiebaud P. Using Propensity Scores to Adjust For Treatment Selection Bias; 2007. http:// www.wuss.org/proceedings08/08WUSS\%20Proceedings/papers/tut/tut09.pdf. Accessed December 18, 2013.

14. Cohen J. Statistical power analysis for the behavioral sciences. Hillsdale, NJ: L. Erlbaum Associates; 1988.

15. Finkelstein J, Eckersberger E, Sadri H, et al. Open versus laparoscopic versus robot-assisted laparoscopic prostatectomy: The European and US experience. Rev Urol 2010;12:35-43.

16. Gore IL, Kwan L, Lee SP, et al. Survivorship beyond convalescence: 48-month quality-of-life outcomes after treatment for localized prostate cancer. J Natl Cancer Inst 2009;101:888-92. http://dx.doi. org/10.1093/inci/dipl14

17. Chen RC, Clark JA, Talcott JA. Individualizing quality-of-life outcomes reporting: How localized prostate cancer treatments affect patients with different levels of baseline urinary, bowel, and sexual function. J Clin Oncol 2009;27:3916-22. http://dx.doi.org/10.1200/JC0.2008.18.6486

18. Tseng TY, Kuebler HR, Cancel QV, et al. Prospective health-related quality-of-life assessment in an initial cohort of patients undergoing robotic radical prostatectomy. Urology 2006;68:1061-6. http://dx.doi. org/10.1016/i.urology.2006.06.017

Correspondence: Dr. Barbara Joyce Davison, College of Nursing, University of Saskatchewan, Saskatoon, SK; joyce.davison@usask.ca 